\title{
Application of Network Teaching and School-enterprise Joint Training Mode in Mechanical Drawing Teaching
}

\author{
Yuanmin Xie ${ }^{1,2,4, a^{*}}$, Lichuan Ning ${ }^{1,2,3, b}$, Guozhang Jiang ${ }^{1,3,4, c}$, \\ Yan Zhou ${ }^{1,2,4, d}$, Gongfa Li ${ }^{1,2,3,4, e}$ and Hao Wu u $^{3, \mathrm{f}}$ \\ ${ }^{1}$ Key Laboratory of Metallurgical Equipment and Control Technology, Ministry of Education, Wuhan \\ University of Science and Technology, Wuhan 430081, China \\ ${ }^{2}$ Hubei Key Laboratory of Mechanical Transmission and Manufacturing Engineering, Wuhan \\ University of Science and Technology, Wuhan 430081, China \\ ${ }^{3}$ Research Center of Biologic Manipulator and Intelligent Measurement and Control, Wuhan \\ University of Science and Technology, Wuhan 430081, China \\ ${ }^{4}$ National Machinery Experimental Teaching Demonstration Center, Wuhan University of Science \\ and Technology, Wuhan 430081, China. \\ a404438295@qq.com, b403366762@qq.com, cwhjgz@wust.edu.cn, d108875266@qq.com, \\ eligongfa@wust.edu.cn, ${ }^{f} 1252334436 @ q q . c o m$
}

Keywords: Mechanical drawing; Teaching reform; Network teaching; School-enterprise joint

\begin{abstract}
At present, there are a series of problems in the mechanical drawing teaching mode of colleges and universities, such as serious shortage of class hours, insufficient interaction between teachers and students, and low enthusiasm for students. At present, all major universities are constantly reforming the teaching mode and seeking better teaching results. In this paper, through using of network teaching and school-enterprise joint training model to seek better teaching results. In response to the questions raised in the text, the text first provides a diversified teaching model through online teaching, which constantly supplements the classroom teaching. In addition, the video deepens the interaction between teachers and students and enhances students' enthusiasm for learning. In addition, through the joint training of schools and enterprises, the students' practice links have been improved. In practice, students have improved their mastery of theoretical knowledge and improved their ability to map and map. Based on this new training mode, the teaching effect has been significantly improved, and the overall ability and quality of students have been improved.
\end{abstract}

\section{Introduction}

The mechanical drawing course is a compulsory basic course for all science and engineering mechanical students. It is a basic course for mechanical students. The study of the second course is closely related to the follow-up professional courses. In today's manufacturing industry, the design, manufacture, and installation of all machines are inseparable from mechanical drawings. Therefore, learning to correctly format the drawings is an extremely important skill. In recent years, along with the changes in the national enrollment policy, colleges and universities have been expanding their enrollment. The previous elite education has also been affected. The quality and theoretical level of graduated college students have generally declined. On the other hand, along with the continuous advancement of science and technology and the transformation and upgrading of the domestic manufacturing structure, the society's requirements for mechanical talents are constantly increasing, requiring them to have more solid theories and related skills, and increasingly demanding of students' drawing skills [1]. In contrast, the education of colleges and universities, the expansion of colleges and universities, but the level of students is uneven, coupled with the compression of college hours, students are more and more difficult to learn mechanical drawing, therefore, colleges and universities urgently need to reform the mechanical drawing curriculum [2]. 


\section{Teaching Status of Mechanical Drawing Courses}

With the continuous advancement of human society and the emergence of new things. In order to provide students with a more comprehensive education, colleges and universities continue to open new courses, so that students are exposed to more cutting-edge knowledge. The course has changed, but the student's total hours have not changed, so the hours allocated to each course have been compressed. The teaching content of the mechanical drawing course is inherently more, and some of the content is abstract and difficult to understand. The compression of class time makes students learning very hard, and this course shows more operability than other courses, but also has a strong practicality. The compression of class time, the speed of the teacher's class is getting faster, and the explanation of the theoretical knowledge in the book is not so detailed. Some of the shallow content, the teachers are all passing by. For the students, all the knowledge in the book is unfamiliar. The teacher's passing and quick explanations make the students more confused and confused about the content of the study. The study of the drawing geometry in mechanical drawing requires a strong spatial imagination [3]. The learning of the drawing geometry is to enhance the students' logical thinking ability from the surface to the surface and from the plane to the space. The compression of class time reduces the time for students and teachers to interact and interact in the classroom. Students can't fully understand the spatial logical thinking ability taught by the teacher, weaken the students' spatial imagination and reduce the understanding of the object space.

In addition, with the increase of education, colleges and universities are expanding the enrollment scale every year. Even for students of the same major, the foundations between students will be quite different. And the expansion of the number of students enrolled, the small class teaching is difficult to implement, most of the courses in colleges and universities use large class teaching. The quality of large class teaching is certainly not as good as small class teaching. The teacher does not have enough energy to take care of every student in the class. Under the existing model training, teachers use the same criteria to treat each student. The students have different foundations and the learning effect will be different. For students with better foundations, the teacher is only a guide. If you give a little touch, the students will understand that for them, the content of the teacher will be understood at a glance, and it will be a waste of time. However, for students with poor foundations, the speed of lectures by teachers is very fast, and the lessons are very difficult to listen to, resulting in no digestion of knowledge [4-5]. At present, the management of colleges and universities is not as severe as that of high schools. Students have entered the university from high school. They have no restrictions on themselves. Therefore, they lack enthusiasm for class. In the classroom, there are phenomena such as sleeping and playing mobile phones. Students don't have enough understanding of the course study. They regard learning as a task that is generally perfunctory, and only wants to do nothing, which leads to a general decline in the quality of college students [6].

In the teaching method of mechanical drawing courses, teachers usually hold textbooks for students to attend classes. Nowadays, classrooms are equipped with multimedia equipment. Teachers are basically combined with some pictures of PPT to explain to students. Occasionally, some physical models will be taken, and specific examples will be given to students. Static picture interpretation does not reflect the process, and students only know the final results. Although the multimedia device is convenient for the teacher to display the work better, there will be some drawing process in the classroom that can be displayed through multimedia. However, the compression of class time and the heavy workload of learning tasks have led to many processes just passing the class, and students are all ignorant. The 45 minutes of the whole class are basically taught by the teacher alone [7]. The students are passively listening below. The students and teachers are in a one-way communication state. Without a good interactive process, it is difficult to mobilize the local enthusiasm of the students and affect the teaching effect. In addition, with the supplement of the university's faculty, a large number of newly graduated doctoral students have been employed as university teachers to participate in the teaching of mechanical drawing courses. They have just stepped out of the school and lacked relevant teaching experience. It is difficult to grasp the key points in teaching, and the teaching effect is not very satisfactory. In the final stage of 
the course study, a test paper is used to determine the learning situation of the course. Some people temporarily hold their feet, start reading a few days before the test, or find someone else to focus on the exam. Such an assessment standard simply does not achieve the desired effect [8].

\section{Reform and Practical Measures}

Reform and practice under the network teaching. In the context of the Internet + , the use of the network is crucial. Relying on the online course, it can effectively solve the problem of severely compressed classes, and also promote the interaction between teachers and students. Online teaching makes full use of network resources. Students can enter the selected course by registering with the teacher of the selected course. At the same time, the teacher list will be displayed on the teacher's side to facilitate teacher management. In the network teaching, the teacher publishes the video of the lecture teaching that he has recorded. The students can watch the contents of the chapters they need according to their own needs and satisfy the students with different foundations. Students with poor foundations can consolidate their knowledge through repeated viewing and learning, and students with better foundations can selectively learn what they need. Online teaching is not limited by time and place. As long as there is a network and a computer, students can learn when they have time [9]. The online teaching video screen provides a way for students to check for missing information. Some students may not be able to attend the class for their own reasons, but they can complete the knowledge supplement through the video screen.

Online teaching is not just a simple uploading of video screens, so that students can learn by themselves, so there is no difference between them and the general network. Online teaching is a supplement to classroom teaching. It is limited by the compression of school hours. The time in class is very valuable, so some tasks are completed by online teaching. In the classroom, the teacher completes the subjective work of teaching, gives students as much as possible to explain the knowledge points, and establishes a holistic framework for the students. In online teaching, students can express their opinions and opinions in the discussion area [10]. Teachers and students interact and exchange without the time limit of the class. The teacher answers questions for the students. Such interactive communication stimulates students' enthusiasm for learning, broadens students' horizons, and deepens their understanding and grasp of knowledge. With the help of communication and dialogue in online teaching, the relationship between teachers and students has been improved. The teaching of knowledge is no longer passively instilled into students, and it has become the active learning of students, stimulating students' curiosity and interest in learning. Even if the teacher can't interact with the student video from time to time, the student can also feedback his question to the teacher in the message area. After the teacher sees it, he will arrange time for the student to answer questions [11]. And after the question in the message area is raised, the students can also discuss each other, which can give students more opportunities to think and learn more.

Online teaching has its own platform. Teachers can publish their own supplementary screens of teaching points in the classroom and the PPT of teaching, so that students can understand the knowledge. In addition, the teacher will also publish a large of pictures related to the course and video screens at home and abroad. Students can watch and learn according to their own interests, understand the current new situation, understand the cutting-edge knowledge of their current professional fields, and broaden their horizons. The study of mechanical drawing courses requires high spatial imagination. In the network teaching, students can see more 3D maps and profiles, present them to students from different angles, enhance the spatial stereoscopic sense of students, and facilitate the training of cartographic courses. The mechanical drawing course cultivates the ability of students to draw, view and map. In addition to imparting theoretical knowledge, online teaching allows students to enhance their ability to view pictures and maps, as well as to strengthen the training of students' drawing skills. Taking full advantage of the convenience of online teaching, teachers often publish some drawing assignments. Students use the online platform to complete the drawing task and submit it to the teacher [12]. The teacher can know the student's true learning status according to the student's submission and explain it in a targeted manner. The teacher will 
point out the mistakes often made by the students, help the students to correct, and fix the review of the knowledge points. In addition, in the course assessment, it should also be assessed from many aspects. The completion and performance of the online teaching curriculum should be included in the final records of the students [13].

Reform and practice of school-enterprise joint training. The cultivation of outstanding students in colleges and universities is to prepare for better entry into the enterprise in the future. The education of college students is inseparable from the needs of enterprises. The education of colleges and universities cultivates the ability of innovation and self-learning of students, but they lack of practical hands-on experience. Through the joint training of schools and enterprises, this problem can be effectively overcome and students' hands-on practical ability can be improved [14]. Although the school also has practice links for mapping and mapping, the teaching effect of this link is not very satisfactory. There are always many drawings that the students finally handed in are a mess and did not achieve the expected results. The training of schools and enterprises can effectively solve the problem of students' lack of practical operation experience. The school cooperates by screening excellent and professional enterprises. The school transports relevant students to the enterprise training and improves students' comprehensive ability. During the practice of the enterprise, the theoretical knowledge that was originally exposed to the school can be used in practical operations, which deepens the students' grasp and understanding of the knowledge in the book. The so-called "paper talks to the end of the shallow", only after the training, students will put this knowledge in their minds, will not forget. Under the joint training of schools and enterprises, it is necessary to make full use of the advantages that enterprises can enable students to practice, to make up for the lack of colleges and universities in this piece [15]. During the joint training period, the professional enterprise engineering technicians and the university teachers should work together to formulate the student training plan, give full play to the strengths of the enterprises and colleges, understand the lack of students, and cooperate with each other to complement each other in practice. Make practice enrich the content of classroom teaching, enhance students' mastery of learning content and exercise students' practical ability.

The nature of the mechanical drawing course is to enable the learner to grasp the characteristics of the mechanical parts, draw the parts in the form of drawings, and reflect all the characteristic relationships of the parts. Beginners often have not touched a lot of parts, and it is difficult to have a perceptual understanding of mechanical parts [16]. It is difficult for students to imagine a two-dimensional figure projected onto a plane through a three-dimensional part. Through the cultivation of the company, students have more opportunities to access various mechanical parts, and deepen their understanding of the parts [17]. Students are not only able to draw a two-dimensional map from a three-dimensional perspective, but also the ability to imagine a three-dimensional map through a two-dimensional map. With the deepening of the practice in the enterprise, the students' understanding gradually deepens and the spatial imagination ability is gradually improved, which can better grasp the difficulties and key points of the drawing course. In the process of cultivating the enterprise, students have many opportunities to draw their own drawings. In the enterprise, they can more effectively train students' ability, can learn a lot of drawing methods and drawing specifications, and after their actual operation, they will be more skilled. In the school, the teacher will also talk about the relevant cartographic specifications, but only limited to the knowledge in the book, only a little related knowledge will be applied in the final course design, resulting in poor final teaching results [18].

\section{Reform Practice Effect of Network Teaching and School-Enterprise Joint Training}

First, with the help of online teaching, it makes up for the shortcomings that are compressed during the teaching class. Students can check the knowledge they have learned through online teaching videos. Wherever they don't understand, they can watch the learning in a targeted manner. And students can review the video over and over and use it as a way to review later. Through online teaching, teachers have more time to interact with students, improve the relationship between 
teachers and students, and promote students' enthusiasm for learning. And the teacher can conduct staged small tests on the students through the online teaching platform to grasp the students' recent learning situation and adjust the teaching arrangements in time. Online teaching is to assist classroom teaching and create better results for classroom teaching. The network teaching has completed a lot of time-consuming work, so the teacher has a stronger target in the classroom teaching process and exerts a better teaching effect. The mode of joint training between schools and enterprises is mainly to exercise students' hands-on practical ability and lay a good foundation for students' comprehensive development. Through the joint training of schools and enterprises, students have a lot of practical hands-on experience in the practice process, deepening the understanding of mechanical parts. And in the process of cultivating the enterprise, the students played an important role in improving the ability of drawing and drawing by hands-on drawing. The reformed teaching process is shown in Fig.1. Through this teaching method, students make full use of the theoretical knowledge acquired in the school, integrate the theory into practice, comprehensively exercise the students' ability of drawing and drawing, and improve the overall quality of the students, and achieve the effect of improving the teaching of mechanical drawing courses [19].

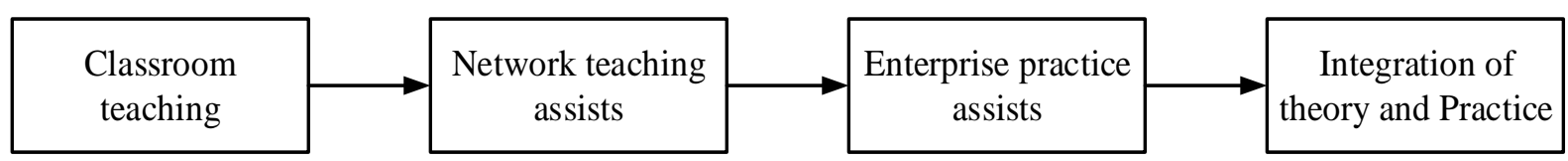

figure 1. Teaching process

Through this reform practice, students' ability to innovate, self-learning, and hands-on operation have been comprehensively improved, improving the teaching effect of mechanical drawing courses and cultivating talents who are more responsive to social needs. In terms of scientific research, the teacher instructed students to actively participate in various mechanical innovation competitions and won dozens of provincial and national awards. In the process of participating in the Innovation Competition, students have obtained dozens of patents or soft patents authorized by the state, which fully demonstrates that students' innovative ability is constantly improving. Students have also participated in the 3D Modeling Competition many times and won several international awards, which fully proves that students have good reading and drawing skills [20]. In addition, in terms of student employment, the employment rate is also steadily increasing, and has been reused by the company after graduation, indicating that the students' ability has been affirmed. The reformed teaching system is self-evident for the improvement of students' ability. The mechanical drawing knowledge has been comprehensively improved and improved, and the students' overall knowledge and culture level has been strengthened.

\section{Conclusions}

This paper puts forward the problems in the teaching of mechanical drawing courses. In response to these problems, this paper proposes the method of network teaching and school-enterprise joint training to reform the mechanical drawing course teaching system. In view of the lack of interaction between teachers and students in the original training mode, the compression of class hours, the lack of students' enthusiasm for learning, and the lack of students' practical experience, the reform plan was put forward and achieved good results. First, through the way of online teaching, students can provide a way to check for missing gaps. Students can self-learn to supplement their knowledge framework. Then through the platform of teachers and students to communicate and interact, improve the relationship between teachers and students, but also for students to answer questions and enhance the students' enthusiasm for learning. Secondly, through the cooperation between schools and enterprises, students enter into excellent enterprises to practice. In the course of practice, a large number of mechanical drawing knowledge learned in the classroom has deepened the students' consolidation of knowledge. At the same time, in the process of practice, the students' 
ability to map and map has been strengthened, and students have achieved comprehensive development. Through the mode of network teaching and school-enterprise joint training, students' mastery of theoretical knowledge, mapping, mapping skills, and hands-on practical ability have all been improved, indicating that the new training model has achieved success. In the new era, the talent training model is constantly changing, and the training of mechanical drawing teaching is constantly advancing with the times, striving to continuously improve the teaching effect.

\section{Acknowledgements}

This work was supported by grants of Teaching Research Project of Hubei Province (based on the teaching reform of Mechanical Design) based on the flipping classroom, project number: 2016230; Wuhan University of Science and Technology Graduate Education Reform Research Project (Relying on the School-Enterprise Joint Training Collaborative Center to strengthen the research on the cultivation of mechanical engineering graduate practice and innovation ability, project number: Yjg201610; Research on the mode of postgraduate training for school-enterprise cooperation for masters of mechanical engineering, project number: Yjg201714); Hubei Province Teaching Research Project (2012218; 2013221; 2015234; 2016230); Teaching Research Project of Wuhan University of Science and Technology (2013059)

\section{References}

[1]. H. Song: Journal of Graphics, Vol. 34 (2013) No.3, p.142-147.

[2]. T.T. Feng, Y.P. Song and L.F. Xu: Education Teaching Forum, (2018).

[3]. L. Wang, N. Wang and Z.F. Niu: Education Teaching Forum, (2017) No.08, p.239-240.

[4]. F.M. Zhang: Education Teaching Forum, (2017) No.07, p.195-196.

[5]. D. Huang: Mechanical Management and Development, Vol. 32 (2017) No.1, p.78-79.

[6]. X.Y. Qin: Science and Technology \& Innovation, (2016) No.23, p.136-138.

[7]. X.G. Wang and L.C. Feng: Journal of Graphics, Vol. 36 (2015) No.6, p.960-965.

[8]. S.H. Lin and P. Yi: Chinese Vocational and Technical Education, (2015) No.26, p.22-25.

[9]. W.H. Yu: Journal of Guangdong Polytechnic Normal University, (2015).

[10]. Y.X. Dan: Journal of Liaoning Institute of Technology, Vol. 17 (2015) No.3, p.138-139.

[11]. W. Yang, J.Y. Zhang, H. Zhang and X.Y. Tong: Journal of Graphics, Vol. 35 (2014) No.1, p.127-130.

[12]. H.X. Song: Journal of Graphics, Vol. 34 (2013) No.3, p.142-147.

[13]. X. Li, Y. Chen and L.X. Xin: Science \& Technology Information, (2013) No.14, P.207-209.

[14]. X.X. Gong and F.C. Sun: Education and Teaching Research, Vol. 26 (2012) No.5, p.73-74.

[15]. F. Xu and C. Chen: China Modern Educational Equipment, (2014) No.9, p.72-73.

[16]. Y. Wu and X. Zhou: The Guide of Science \& Education, (2014) No.25, p.157-158.

[17]. Y.Q. Lin and B.B. Ma: Journal of Taizhou Polytechnical College, (2015) No.1, p.11-13.

[18]. Y.L. Zhang: Occupation, (2016) No.11, p.97-98.

[19]. Y.X. Sun: Science and Technology Innovation Herald, (2017) No.21, p.219-220.

[20]. X.M. Zhou, L. Xiao, J. Wang and Y. Wang: Journal of Higher Education, (2018) No.5, p.165-137. 